\title{
VIDEO PEMBELAJARAN BERBASIS SPARKOL VIDEOSCRIBE: INOVASI PADA PERKULIAHAN SEJARAH MATEMATIKA
}

\author{
${ }^{1}$ Aan Subhan Pamungkas, ${ }^{2}$ Ihsanudin, ${ }^{3}$ Novaliyosi, ${ }^{4}$ Indhira Asih Vivi Yandari \\ ${ }_{1,2,3,4}$ Pendidikan Matematika FKIP Universitas Sultan Ageng Tirtayasa, Jl Raya Jakarta Km 4 Pakupatan Serang \\ e-mail: asubhanp@untirta.ac.id
}

\begin{abstract}
Abstrak
Video pembelajaran merupakan salah satu jenis media yang mengutamakan kekuatan suara dan gambar. Sejarah matematika merupakan mata kuliah pilihan dimana jenis materi dalam mata kuliah ini bersifat faktual, sehingga dalam proses pembelajarannya dosen lebih mengedepankan metode ceramah, presentasi dan diskusi. Untuk lebih mengefektifkan proses perkuliahan maka akan disusun suatu inovasi pembelajaran yaitu dengan mengembangkan video pembelajaran berbantuan aplikasi sparkol videoscribe. Tujuan utama dari penelitian ini adalah mengembangkan video pembelajaran berbantuan aplikasi sparkol videoscribe pada mata kuliah sejarah matematika serta mendeskirpsikan langkah pembelajaran yang mendukungnya. Penelitian ini merupakan penelitian pengembangan yang meliputi tahap concept, design, collecting materials, assembly, test drive dan distribution. Kelayakan pengembangan video pembelajaran diperoleh berdasarkan data dari angket yang kemudian dianalisis secara deskriptif kuantitatif. Penilaian ahli isi mata kuliah mencapai kategori baik, ahli media pembelajaran mencapai kategori baik dan validasi kelompok kecil mencapai kategori baik. Adapun langkah pembelajaran yang dilaksanakan di kelas sebagai berikut: Pendahuluan: membagi mahasiswa ke dalam beberapa kelompok; Inti: Mengamati video, membuat pertanyaan/tanggapan, dan dikusi kelompok; Akhir: kesimpulan dan refleksi.
\end{abstract}

Kata Kunci: Video Pembelajaran, Sparkol Videoscribe, Sejarah Matematika

\begin{abstract}
Video learning is one type of media that prioritizes the power of sound and image. The type of Knowledge in the history of mathematics is factual, so that in the learning process lecturers put forward the methods of lectures, presentations and discussions. To further streamline the lecture process then developed a learning innovation learning-assisted video applications sparkol videoscribe. The main objective of this research is to develop a learning application-assisted video sparkol videoscribe in mathematical history courses as well as describe the steps of learning that supports it. Stages of development include the stage of concept, design, collecting materials, assembly, test drive and distribution. The feasibility of developing learning videos is obtained based on data from questionnaires which are then analyzed descriptively quantitatively. The expert assessment of the content of the subjects reached the good category, the learning media expert reached the good category and the small group validation achieved the good category. As for learning the steps implemented in classes as follows: Introduction: divide students into several groups; Core: Watched the video, make inquiries/responses, and dikusi group; Final conclusions and reflections.
\end{abstract}

Keywords: Learning Video, Sparkol Videoscribe, History of Mathematics.

\section{PENDAHULUAN}

Perkembangan teknologi saat ini mendorong perubahan dalam segala bidang kehidupan, termasuk bidang pendidikan. Pendidikan dalam ruang lingkup sempit merujuk pada proses pembelajaran di kelas yang diselenggarakan oleh pendidik.

Pembelajaran yang sesuai dengan perkembangan jaman sekarang harus mengintegrasikan dengan teknologi informasi dan komunikasi. Sehingga pendidik harus mempunyai kemampuan dalam mengembangkan media berbasis teknologi. Hal ini 
dimaksudkan agar terciptanya inovasi dalam pembelajaran di kelas. Sehingga peran ICT menjadi sangat penting dalam proses pembelajaran.

Pendapat di atas sejalan dengan Bingimlas, K.A (2009) yang menyatakan bahwa the use of ICT in the classroom is very important to providing opportunities for students to learn to operate in information age. Sejalan dengan pendapat tersebut Lefebvre, Deaudelin \& Leiselle, 2006; Dawes, 2001) yang menyatakan bahwa teknologi modern menawarkan perubahan pada proses pembelajaran di kelas dan mempunyai potensi untuk mendukung pendidikan lintas kurikulum dan memberikan kesempatan yang efektif dalam komunikasi antara guru dan siswa.

Pendapat tersebut menegaskan bahwa pada era informasi seperti sekarang ini, penggunaan ICT dalam pembelajaran di kelas mutlak harus dilakukan oleh pendidik.

Penggunaan ICT di kelas dalam rangka menyiapkan siswa yang mampu menerima, mengolah, dan menyebarkan informasi yang melimpah ruah.

Selain itu dalam rangka menghadapi perkembangan abad 21 masyarakat harus "to develop skills, content knowledge, and social and emotional competencies to navigate complex life and work environments. Essential life and career skills include: Flexibility \& Adaptability; Initiative \& Self Direction; Social \& Cross-Cultural Skills; Productivity \& Accountability" (P21 ${ }^{\text {st }}$ Century Learning, 2007). Dari beberapa pendapat di atas, maka sangat jelas bahwa peran ICT dalam menyipakan sumber daya yang berdaya saing. Dalam rangka mengintegrasikan ICT dalam pembelajaran, maka dilakukan inovasi pembelajaran dengan mengembangkan video pembelajaran pada perkuliahan sejarah matematika.

Sejarah matematika merupakan mata kuliah pilihan pada Program Studi Pendidikan Matematika FKIP Universitas Sultan Ageng Tirtayasa. Pengetahuan pada mata kuliah ini bersifat faktual, sehingga pola pembelajaran cenderung informatif dengan setting pembelajaran yaitu mahasiswa menyajikan materi dengan presentasi menggunakan power point. Guru hanya sebagai fasilitator dan kolaborator. Kegiatan pembelajaran seperti pada penjelasan di atas cenderung membuat mahasiswa monoton dan kurang aktif. Beranjak pada fakta tersebut maka dosen perlu melakukan inovasi pembelajaran yang sesuai dengan kebiasan dan perkembangan terkini.

Inovasi pembelajaran dilakukan pada aspek sumber belajar. Menurut Association for Educational Communication and Technology (1977) learning resources all of the resources (data, people, and things) which may be used by the learner in isolation or in combination, usually in an informal manner, to facilitate learnig. 
Pendapat tersebut sejalan dengan PEI Department of Education (2008) yang menyatakan bahwa "learning Resources refer to any person(s) or any material (whether acquired or locally produced) with instructional content or function that is used for formal or informal teaching/learning purposes. Learning resources may include, but are not limited to, print and non-print materials; audio, visual, electronic, and digital hardware/software resources; and human resources".

Dari kedua pendapat di atas, dapat dibuat kesimpulan bahwa sumber belajar adalah segala sesuatu yang dapat digunakan oleh siswa baik secara sendiri maupun dikombinasikan dengan tujuan memfasilitasi proses belajar. Sumber belajar dalam hal ini tidak terbatas pada bentuk cetak dan non cetak, tetapi bisa berupa software atau hardware. Peran sumber belajar dalam sistem pembelajaran merupakan komponen yang penting diantara tujuan, materi, metode dan evaluasi. Karena tanpa sumber belajar tujuan pembelajaran dalam sebuah sistem tidak akan tercapai.

Salah satu jenis sumber belajar yang berfungsi sebagai perantara dalam menyampaikan informasi dalam proses pembelajaran adalah media teknologi. Menurut (Reeves, Thomas C, 1998; Omodara \& Adu, 2014) media defined as "all means of communication, whatever its format." In this sense, media include symbol systems as diverse as print, graphics, animation, audio, and motion pictures. Technology is defined as "any object or process of human origin that can be used to convey media." In this sense, technology includes phenomena as diverse as books, films, television, and the Internet. Sedangkan menurut (Nas Ahsan Akhtar \& Akbar Rafaqat Ali) Media are the means for transmitting or delivering messages and in teachinglearning perspective delivering content to the learners, to achieve effective instruction.

Berdasarkan pendapat di atas, media pembelajaran adalah segala sesuatu yang digunakan untuk menyampaikan pesan yang dapat merangsang pikiran, perasaan, perhatian serta rasa ingin tahu siswa, sehingga mendorong terjadi proses belajar dari dalam dirinya dan tujuan pembelajaran dapat dicapai dengan mudah.

Salah satu bentuk media pembelajaran yang mempunyai keunggulan dalam aspek audio dan visual adalah video pembelajaran. Melalui video pembelajaran materi disampaikan dalam bentuk cerita yang utuh. Menurut Deakin Learning Futures Teaching Development Team (2014) Audio and video materials can be used to enhance learning resources by showing real life scenarios, explaining concepts, observing social groups, and acting as triggers for discussion. They are also able to bring experts and viewpoints to the student learning 
experience and are excellent at bringing subjects 'to life' to engage discussion and inspire learning.

Dari pendapat di atas dijelaskan bahwa video pembelajaran dapat menjelaskan konsep dan sebagai pemicu diskusi antar siswa. sehingga pada saat pembelajaran memanfaatkan video terjadi interaksi antara siswa dan siswa, siswa dan guru serta siswa dan sumber belajar.

Selain itu menurut D Deakin Learning Futures Teaching Development Team (2014) Video is also a popular tool used to engage learners and enhance a learning experience. Anyone with a digital camera, webcam, tablet or smartphone can now create and edit a movie. YouTube statistics highlight the widespread use of video online, with more than 4 billion hours of video watched each month and 72 hours of video being uploaded every minute (YouTube 2013, statistics). Videos are an excellent way to present and elaborate concepts, demonstrate a procedure or gain an understanding of learning in action.

Dari fakta di atas menunjukkan bahwa penggunaan video sangat populer dan sangat dimungkinkan dimanfaatkan dengan baik dalam proses pembelajaran di kelas. Dengan demikian berdasarkan uraian di atas, maka dapat kita lihat bahwa manfaat penggunaan video pembelajaran sangat penting agar tujuan pembelajaran yang diinginkan oleh guru tercapai dengan baik. Berkaitan dengan konsep yang abstrak, maka peran video pembelajaran sangat membantu dalam mendeskripsikan secara konkret konsep tersebut melalui ilustrasi yang baik. Seiring berkembangnya teknologi informasi dan komunikasi, maka berkembang pula media pembelajaran yang berbasis teknologi salah satu aplikasi yang bisa dimanfaatkan dalam pengembangan video pembelajaran adalah aplikasi sparkol videoscribe.

Sparkol videoscribe merupakan sebuah media pembelajaran video animasi yang tersiri dari rangkaian gambar yang disusun menjadi sebuah video utuh. Dengan karakteristik yang unik, sparkol videoscribe mampu menyajikan konten pembelajaran dengan memadukan gambar, suara dan desain yang menarik sehingga siswa mampu menikmati proses pembelajaran. Fitur yang disediakan oleh aplikasi ini sangat beragam sehingga mampu menjadi media pembelajaran yang dapat disesuaikan dengan mata kuliah yang diinginkan. Selain menggunakan deisain yang telah disediakan didalam aplikasi, pengguna dapat membuat desain animasi, grafis, maupun gambar yang sesuai dengan kebutuhan kemudian diimport ke dalam aplikas tersebut.

Selain itu, pengguna juga dapat melakukan dubbing dan memasukkan suara sesuai kebutuhan untuk membuat video. Pembuatan videoscribe juga daapt dilakukan secara offline sehingga tidak tergantung pada layanan internet, hal ini pastinya akan lebih memudahkan 
pengembangan dalam membuat media pembelajaran menggunakan aplikasi sparkol videoscribe. Berdasarkan penjelasan di atas, maka tujuan dari penelitian ini adalah mengembangkan video pembelajaran berbantuan videoscribe serta mendeskripsikan langkah pembelajaran yang mendukungnya.

\section{METODE PENELITIAN}

Penelitian ini bertujuan untuk menghasilkan suatu produk yaitu video pembelajaran berbantuan aplikasi sparkol videoscribe yang bisa dimanfaatkan dalam proses perkuliahan sejarah matematika sehingga penelitian yang akan dilaksanakan adalah penelitian pengembangan (Development Research).

Prosedur penelitian pengembangan terdiri atas enam tahap yaitu: (1) Concept: Pada tahap ini kegiatan yang dilakukan adalah menentukan materi, tujuan dan perumusan indikator yang nantinya akan dicapai setelah materi ajar disampaikan; (2) Design: Perancangan media yang akan dikembangkan yang dalam hal ini adalah video pembelajaran meliputi naskah dan pemilihan software yang akan digunakan dalam pembuatan media; (3) Collecting Materials: Tahap ini adalah pengumpulan materi ajar yang akan dimasukkan ke dalam video pembelajaran; (4) Assembly: Tahap ini dikenal dengan tahap pembuatan produk. Produk yang dibuat didasarkan pada naskah yang telah dirancang pada tahap design; (5) Test Drive and Distribution: Pada tahap ini setelah produk selesai dibuat. Selanjutnya produk divalidasi oleh reviewer yaitu ahli konten dan ahli media, uji ini bertujuan untuk menilai kelayakan produk yang telah dikembangkan.

Metode pengumpulan data yang digunakan dalam penelitian ini adalah angket ahli. Angket digunakan untuk mengumpulkan data hasil review dari ahli konten dan media. Analisis dalam penelitian ini adalah analisis deskriptif kuantitatif.

Analisis deskriptif kuantitatif ini digunakan untuk mengolah data yang diperoleh melalui angket dalam bentuk deskriptif. Rumus yang digunakan menurut Tegeh dan Kirna (2010) dengan kualifikasi sebagai berikut.

\begin{tabular}{|c|c|}
\hline Kriteria (\%) & Criteria \\
\hline $90<\mathrm{P} \leq 100$ & Sangat Baik \\
\hline $75<\mathrm{P} \leq 90$ & Baik \\
\hline $65<\mathrm{P} \leq 75$ & Cukup \\
\hline $55<\mathrm{P} \leq 65$ & Kurang \\
\hline $0<\mathrm{P} \leq 55$ & $\begin{array}{c}\text { Sangat } \\
\text { Kurang }\end{array}$ \\
\hline
\end{tabular}




\section{HASIL DAN PEMBAHASAN}

Hasil penelitian pada pengembangan video pembelajaran ini dilakukan berdasarkan prosedur pengembangan dengan tahapan Concept, Design, Collecting Materials, Assembly dan Test Drive and Distribution.

Concept; pengembangan konsep dilakukan dengan identifikasi materi, merumuskan capaian pembelajaran sesuai RPS serta menerapkan indicator. Materi yang diangkat dalam video ini adalah Matematika empiris, matematika kontemporer, perkembangan sebelum dan sesudah renaissance, aksioma dan proporsi matematika, peran logika dalam system matematika, landasan dan paradox dalam matematika, macam-macam aliran dalam membangun landasan, matematika sebagai metode serta seni keindahan.

Design; memilih dan menetapkan aplikasi yang digunakan yaitu sparkol videoscribe dan mengembangkan naskah untuk memvisualisasikan alur kerja produk mulai awal hingga akhir. Collecting Materials; pada tahap ini kegiatan yang dilakukan adalah pengumpulan bahan atau materi ajar yang sudah ditentukan pada tahap pertama, aspek pendukung seperti gambar animasi, audio, atau image. Assembly; menyusun naskah materi pembelajaran yang dimasukkan pada setiap topik. Berikut adalah cuplikan gambar video pembelajaran berbasis sparkol video scribe.
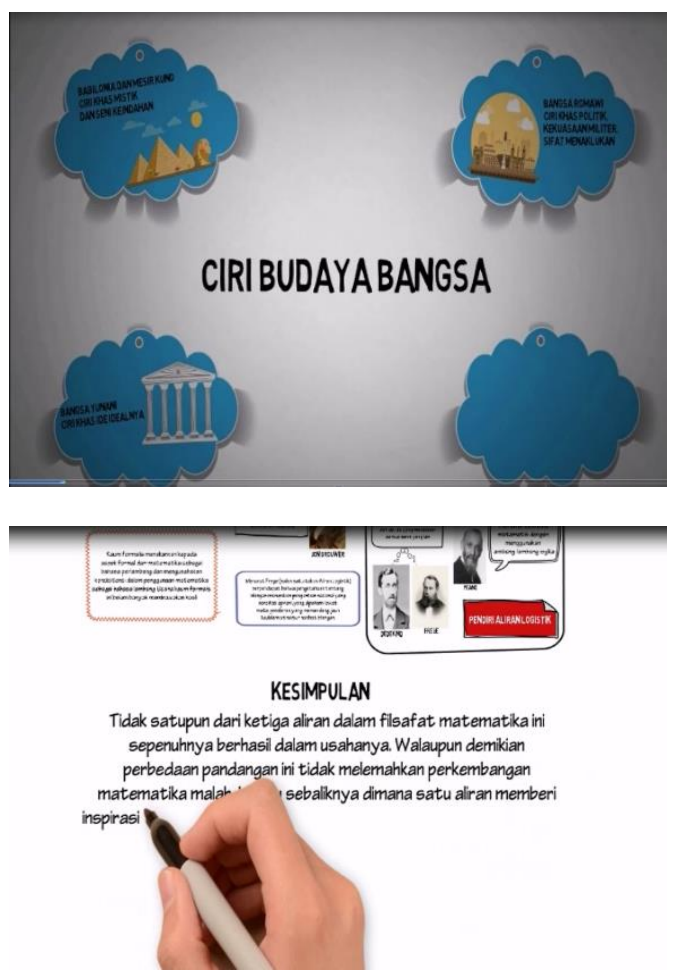

Prima, Vol. 2, No. 2, Juli 2018, 127 - 135 

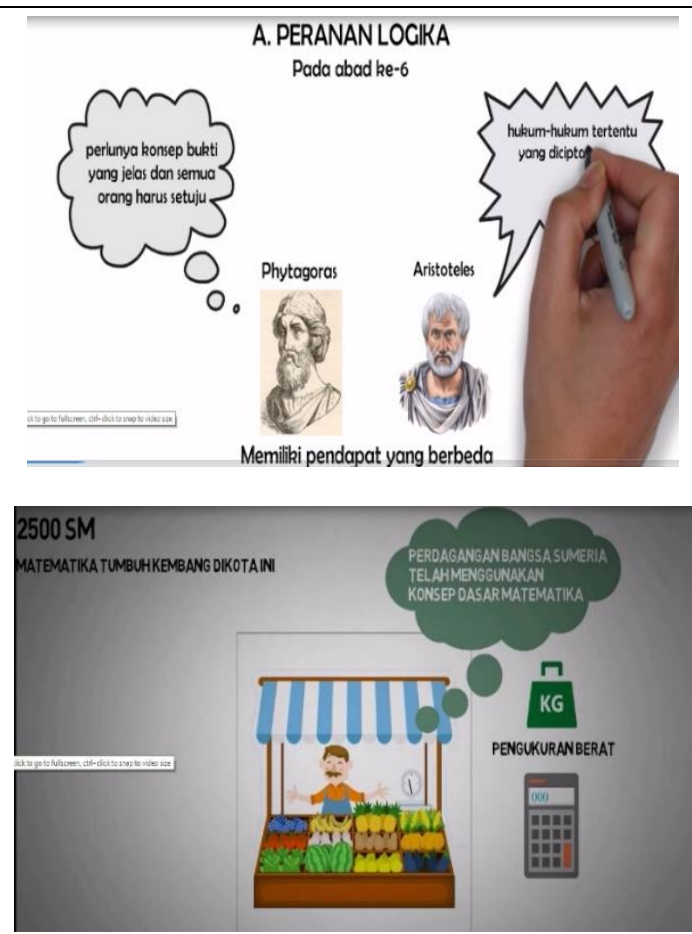

Test drive and distribution; untuk melihat sejauh mana produk yang dibuat dapat mencapai sasaran dan tujuan. Kegiatan uji kevalidan dan kepraktisan dilakukan pada tahapan ini. Berikut tabel hasil uji ahli materi dan media.

Tabel 2. Result of Content Expert Judgement

\begin{tabular}{|c|c|c|c|c|c|}
\hline No & Aspek & Skor & Max & $\%$ & Criteria \\
\hline 1 & Media & 31 & 36 & 86,11 & Very Good \\
\hline 2 & Materi & 14 & 16 & 87,50 & Very Good \\
\hline
\end{tabular}

Tabel 3. Result of Media Expert Judgement

\begin{tabular}{|c|c|c|c|c|c|}
\hline No & Aspek & Skor & Max & \% & Criteria \\
\hline 1 & Mutu Teknis & 17 & 20 & 85,00 & Very Good \\
\hline 2 & Media & 45 & 52 & 86,54 & Very Good \\
\hline
\end{tabular}

Berdasarkan hasil uji validasi yang dilakukan oleh ahli materi dan media, kedua ahli menyatakan bahwa produk yang dikembangkan layak digunakan untuk perkuliahan sejarah matematika. Adapun hasil uji kepraktisan yang meliputi keterbacan dan kepraktisan pengguna yang dilakukan oleh dosen dan mahasiswa menyatakan bahwa produk yang dikembangkan cukup praktis digunakan baik oleh dosen dan mahasiswa.

Adapun langkah-langkah pembelajaran yang terapkan pada perluliahan sejarah matematika dengan menggunakan videoscribe ini sebagai berikut:

\section{Tahap Pembuatan Proyek:}

1. Dosen membagi mahasiswa ke dalam beberapa kelompok.

2. Tiap kelompok mendapatkan satu topik sejarah matematika.

3. Tiap kelompok diwajibkan untuk membuat materi presentasi dengan format videoscribe 


\section{Tahap Pra Perkuliahan:}

1. Tiap kelompok mengumpulkan video pembelajaran.

2. Dosen memberikan review terkait video yang telah dibuat mahasiswa.

3. Mahasiswa merevisi video sesuai masukan dosen.

4. Mahasiswa mengupload video pembelajaran pada saluran youtube.

5. Mahasiswa mempelajari video sesuai dengan materi yang akan dibahas pada pertemuan berikutnya.

\section{Tahap Perkuliahan:}

1. Mahasiswa menyajikan materi presentasi yang ada dalam video

2. Mahasiswa kelompok lain menyimak dan membuat pertanyaan

3. Mahasiswa memimpin diskusi kelas

4. Dosen memberikan tanggapan dan penguatan kepada mahasiswa

\section{Tahap Penutup:}

1. Mahasiswa bersama dosen membuat kesimpulan

2. Mahasiswa melakukan refleksi terkait pelaksanaan pembelajaran yang sudah dilakukan

\section{SIMPULAN DAN SARAN}

Berdasarkan pembahasan di atas, maka dapat disimpulkan bahwa produk video pembelajaran yang dikembangkan termasuk kategori baik dan layak menurut penilaian para ahli. Adapun langkah pembelajaran secara garis besar terdiri dari tahapan pembuatan proyek, pra perkuliahan, perkuliahan dan tahap penutup.

\section{DAFTAR PUSTAKA}

Association of Educational Communication and Technology. 1977. The Definition of Educational Technology. Washington DC.

Bingimlas, K. A. (2009). Barriers to the successful integration of ICT in teaching and learning environments: A review of the literature. Eurasia journal of mathematics, science \& technology education, 5(3).

Deakin Learning Futures Teaching Development Team. 2014. Using audio and video for educational purposes. Available at: deakin.edu.au/learning-futures.

Lefebvre, S., Deaudelin, D., \& Loiselle, J. (2006, November). ICT implementation stages of primary school teachers: The practices and conceptions of teaching and learning. In Australian Association for Research in Education National Conference, Adelaide, Australia. 
Naz Ahsan Akhtar \& Akbar Rafaqat Ali. Use of Media for Effective Instruction its Importance:

Some Consideration. Journal of Elementary Education. A Publication of Deptt. of Elementary Education IER, University of the Punjab, Lahore - Pakistan Vol. 18(1-2) $35-40$.

Omodara O.D \& Adu E.I. Relevance of Educational Media and Multimedia Technology for Effective Service Delivery in Teaching and Learning Processes. IOSR Journal of Research \& Method in Education (IOSR-JRME). e-ISSN: 2320-7388,p-ISSN: 2320$737 X$ Volume 4, Issue 2 Ver. I (Mar-Apr. 2014), PP 48-51 www.iosrjournals.org

Partnership for $21^{\text {st }}$ Century Learning. 2007. Framework for $21^{\text {st }}$ Century Learning. Washington DC. Available at http://www.p21.org/storage/documents/docs/P21_framework_0816.pdf. 